\title{
- Plano de Ações Articuladas e o regime de cola- boração na gestão educacional em municípios paraenses
}

\author{
Laurimar de Matos Farias \\ Secretaria Estadual de Educação \\ Universidade Federal do Pará \\ Vera Lúcia Jacob Chaves \\ Universidade Federal do Pará \\ Valéria Silva de Moraes Novais \\ Universidade do Estado do Amapá
}

\section{Resumo}

O regime de colaboração fixado na CF/1988, visa determinar o compartithamento do poder entre os entes federativos. No que tange à educação, esse regime tem se estabelecido principalmente por meio de programas implantados pelo governo federal como o Plano de Ações Articuladas (PAR), com o argumento de melhoria da educação básica. Este artigo tem por objetivo analisar as características do regime de 220 colaboração instituídas no desenvolvimento do PAR tendo como foco de análise a dimensão da gestão educacional em cinco municípios paraenses. Para o desenvolvimento da pesquisa foram realizadas análise documental e entrevistas semiestruturadas com 39 sujeitos que atuaram na elaboração do PAR. Os dados coletados foram analisados tendo como base as categorias autonomia e participação. $\bigcirc$ estudo evidenciou que predomina uma concepção de gestão centralizada e verticalizada que não se coaduna como uma efetiva ação pública que promova, conforme prevê a constituição, um verdadeiro regime de colaboração.

Palavras-chave: Regime de colaboração. Plano de Ações Articuladas. Gestão educacional.

\section{The Plan of Articulated Actions and the regime of collaboration in the educational management in cities of Pará}

\section{Abstract}

The regime of collaboration established in the Federal Constitution of 1988 aims to determinate the sharing of power among federative persons. Talking about education, this regime is being established by programs implemented by the Federal Government such as the Plan of Articulated Actions (PAR in Portuguese), promising to make the elementary education better. This paper aims to analyze the characteristics of this regime 
of collaboration established on the PAR's development, having as an analyze focus the dimension of the educational management in five cities of Pará. To develop this research, an educational analyze and semi-structured interviews with thirty-nine (39) persons that helped the PAR to be elaborated were performed. The data collected were analyzed having a basis the categories autonomy and participation. The study showed that the predominance is of a conception of centralized and verticalized management, which one is not in line as an effective public action promoting, as the constitution expects, a true regime of collaboration.

Keywords: Regime of collaboration. Plan of articulated actions. Educational management.

\section{El Plan de las Acciones Articuladas y el régimen de la colaboración en la gestión educacional en los municipios paraenses}

\section{Resumen}

El régimen de colaboración fijado en la CF/1988, busca determinar el reparto del poder entre los entes federativos. En lo que se refiere a la educación, este régimen se ha establecido principalmente por medio de programas implantados por el gobierno federal como el Plan de Acciones Articuladas (PAR), con el argumento de mejora de la educación básica. Este artículo tiene por objetivo analizar las características del régimen de colaboración instituidas en el desarrollo del PAR teniendo como foco de análisis la dimensión de la gestión educativa en cinco municipios paraenses. Para el desarrollo de la investigación se realizaron análisis documental y entrevistas semiestructuradas con 39 sujetos que actuaron en la elaboración del PAR. Los datos recolectados fueron analizados teniendo como base las categorías autonomía y participación. El estudio evidenció que predomina una concepción de gestión centralizada y verticalizada que no se acoge como una efectiva acción pública que promueva, según prevé la constitución, un verdadero régimen de colaboración.

Palabras clave: Régimen de colaboración. Plan de acción articuladas. Gestión educacional

\section{Introdução}

Este artigo analisa as características do regime de colaboração, efetivadas por intermédio do Plano de Ações Articuladas - PAR em cinco municípios paraenses ${ }^{1}$, no que tange à dimensão da gestão educacional. $\bigcirc$ texto apresenta parte dos resultados da pesquisa acerca da Avaliação do Plano de 
O plano de ações articuladas e o regime de colaboração na gestão educacional em municípios paraenses

Ações Articuladas - PAR: um estudo em municípios do Rio Grande do Norte, Pará e Minas Gerais no período de 2007 a 20112.

regime de colaboração - importante categoria de análise para a pesquisa supracitada - se fundamenta, a priori, numa relação da gestão colaborativa, cuja engrenagem deve funcionar de modo articulado dentro de uma totalidade ordenada, isto é, trata-se de um conceito estreitamente ligado ao de princípio federativo, e não deve comportar relações hierárquicas entre as esferas do poder político, visto que está calcado na ideia da relação entre iguais. Assim, entre União, Estados, Distrito Federal e Municípios, não deve haver relação de subordinação, por se constituírem entes federados iguais, tal qual prevista na legislação que a fundamenta.

Dessa forma, a negociação coletiva, o compartilhamento de poder, a autonomia e as tomadas de decisões horizontalizadas podem ser encaradas como peças centrais na efetivação das relações que concretizam o regime de colaboração ${ }^{3}$. A colaboração, nesse formato, passa a incorporar aspectos, além da mera execução, e assume práticas de participação na criação, na interposição decisória nos destinos das políticas e nas suas formas de materialização, além da tomada de posição concreta na sua execução por todas

222 as unidades governamentais que compõem o sistema federativo (ABRUCIO, 2010).

Nas orientações da atual política para a gestão da educação, o PAR é considerado "[...] o conjunto articulado de ações, apoiado técnica ou financeiramente pelo Ministério da Educação, que visa ao cumprimento das metas do Compromisso e a observância das suas diretrizes" (BRASIL, 2007). A concretização das diretrizes do Plano de Metas Compromisso Todos Pela Educação requer o comprometimento dos gestores em nível local por meio da assinatura de um Termo de Adesão ao compromisso e se dá na construção ou preenchimento do Plano de Ações Articuladas de cada ente municipal.

PAR se fundamenta em princípios de um modelo de gestão que tem privilegiado as parcerias entre todos os entes da federação promovendo, entre outras, a desconcentração de poder e do financiamento, configurando um plano que alterna dois modelos de gestão - a democrática e a gerencial, caracterizada por Camini (2009) como gestão híbrida (misto de democrática e gerencialista). 
Esse hibridismo de modelo de gestão pública caracteriza modelos em transição e, por vezes, fragilizados, típico "[...] da Nova Gestão Pública, apesar de serem absorvidas sem resistências, supõem a adaptação de parâmetros do modelo de Estado residual ou do Estado híbrido aparentemente progressista" (CAMINI, 2009, p. 107). Nessa perspectiva, o PAR se fundamenta, ao mesmo tempo, num modelo de gestão compartilhada mediante a defesa de mecanismos democráticos, como a efetivação de conselhos escolares, e num modelo gerencial, fruto do ideário neoliberal de gestão em que se propõe a melhorar os índices de qualidade mantendo a centralidade nas decisões e o prevalecimento da busca por resultados com base em índices, indicadores e critérios a serem alcançados.

$\bigcirc$ próprio termo de adesão ao PAR impõe que os entes federativos concentrem esforços na busca de atendimento aos índices do Índice de Desenvolvimento da Educação Básica - Ideb - projetados para cada ano da educação básica e de melhorias contínuas dos índices por escola, mas não considera a realidade de cada escola ou sistema, ou seja, o modelo proposto pelo PAR exige que os entes federados se adaptem ao modelo informatizado previamente definido e não permite que o sistema se amolde as necessidades e realidades de cada um.

Com base nessas reflexões iniciais, este trabalho teve por objetivo analisar as características do regime de colaboração estabelecidas no desenvolvimento do PAR tendo, como foco de análise, a dimensão da gestão educacional em cinco municípios paraenses. Para tanto, buscamos respostas às seguintes questões: Que relações prevalecem no regime de colaboração entre os entes federativos, firmado por meio do PAR, cooperação ou responsabilização? Como vem se efetivando o regime de colaboração entre o governo federal e cinco municípios paraenses tendo como foco a dimensão da gestão educacional?

A organização do texto compreende duas seções. Na primeira, discorremos sobre os fundamentos do regime de colaboração e como vem se articulando com a política educacional nos últimos anos, tendo como base de análise os estudos efetivados por Werler (2006); Camini (2010); Abrucio (2010) e Luck (2010). Na segunda parte do texto, apresentamos os resultados da pesquisa realizada sobre a dimensão gestão educacional presente no PAR de cinco municípios paraenses (Altamira, Barcarena, Belém, Cametá e Castanhal) tendo como base a análise dos documentos e das entrevistas 
O plano de ações articuladas e o regime de colaboração na gestão educacional em municípios paraenses

realizadas com 39 sujeitos, distribuídos pelos municípios de Altamira (15), Barcarena (03), Belém (07), Cametá (07) e Castanhal (07), entre técnicos das secretarias, ex-secretários de educação, conselheiros municipais de educação, membros da diretoria de sindicatos e técnicos de planejamento. Na conclusão, refletimos sobre as relações existentes no regime de colaboração celebrado entre o governo federal e municípios paraenses, articulando com o modelo de gestão assumido com base na mediação com o PAR.

\section{Breves incursões sobre o regime de colaboração enquanto princípio federativo e sua articulação com a política educacional}

A discussão sobre os princípios basilares que envolvem o conceito de regime de colaboração no sistema nacional e seu aparelhamento político-administrativo implica a necessidade da definição de um significado distinto desse termo, considerando sua intencionalidade organizativa e sua importância para a consecução da gestão do aparato estatal. Neste sentido, com base nas contribuições da literatura consultada, expomos, em linhas gerais, o significado dos dois termos que compõem esse modelo administrativo, quais sejam:

224 regime e colaboração.

Werle (2006, p. 23) ao discorrer sobre essa temática, explica que o termo regime vem do latim regimen que significa "[...] ação de guiar, de governo, de direção". E que esse termo diz respeito ao "modo de administrar, regra ou sistema, regulamento". Em suma, essas definições do termo regime referem-se, em especial, a um esforço concentrado entre todos os membros de uma federação ou de governo na ação da gestão colaborativa, em que os princípios da descentralização de poder e de decisões, da autonomia política e administrativa devem ser a mola motriz das relações institucionais.

As responsabilidades e corresponsabilidades na direção da efetivação de um regime colaborativo, no atendimento às especificidades da educação básica, de modo que essas relações de interesses não sobrepujam as individualidades e considerem, sobretudo, as capacidades financeiras de cada ente, devem ser bem definidas, para não ferir a autonomia dos entes regionais e nem os tornar reféns das determinações do governo central, pois, além de "[...] simples transferência administrativa e burocrática de responsabilidade, a corresponsabilidade significa uma vontade política conjunta de 
resolver os problemas do ensino básico, dentro das possibilidades de cada esfera administrativa" (HAGUETE, 1989, p. 27).

$\bigcirc$ modelo atual do regime de colaboração, se considerarmos as definições do termo "regime", é contraditório. As relações exercidas, especialmente pelo governo central, na elaboração de políticas educacionais, a partir da década de 1990, afetam os preceitos basilares da autonomia dos demais entes federativos e, o esforço comum que deveria ser implementado pelo conjunto dos membros partícipes da federação, acaba por se resumir a simples execução dos planos e programas federais, via transferências aos membros regionais, em que os Municípios, nas principais políticas, são os mais penalizados.

Nesse contexto, é fundamental que a autonomia seja a base das relações estabelecidas entre os entes federados e não a subordinação ou a "[...] imposição de decisões inclusive a simples transferência de encargos no trato de questões comuns" (WERLE, 2006, p. 23).

Quanto ao termo colaboração, esse implica, conceitualmente, em: "[...] trabalhar na mesma obra, cooperar, interagir com outros [...] contribuir, assumir responsabilidades, ter parte nos resultados e em compromisso e despesas comuns" (WERLE, 2006, p. 23). Essa autora argumenta, ainda, que a colaboração implica, sobretudo, que todas as proposições e decisões tomadas sobre uma determinada política pública que comprometa o envolvimento dos entes federativos, devam ser conjuntas e comuns, isto é, colaborar, sugere a igualdade de competências e tomadas de decisões.

Em face disso, a autora define, em linhas gerais, um conceito basilar do desenvolvimento e o que, de fato, seja o regime de colaboração, afirmando que este é:

$\bigcirc$ processo colaborativo que se constrói com envolvimento de todos, numa perspectiva democrática cidadã, cujas bases não se restringem a documentos formais, mas que compreende a importância de uma cultura de colaboração entre redes sistemas, entre executivo e legislativo municipal, entre órgãos normativos dos sistemas de ensino e de todos os envolvidos (WERLE, 2006, p. 9).

Ao considerarmos essa corresponsabilidade na implementação de políticas públicas e a cumplicidade dos entes federativos na promoção de planos e programas educacionais comuns a cada ente, concordamos com Cassini 
(201 1 , p. 68, grifos da autora) quando assevera que a colaboração configura "[...] um instituto obrigatório, não vulnerável a uma 'possível adesão'e, dessa forma, não corre o risco de ser mais um instrumento sujeito ao jogo defensivo e colaborativo das unidades subnacionais"

A autora defende que um Estado no qual se proponha, em suas ações governativas uma relação de colaboração, em que cada membro da federação seja coparticipante na promoção de políticas educacionais, deve ser um Estado que promova uma mais efetiva interação entre os entes federativos, proporcionando, sobretudo, a garantia de maior autonomia, sem o risco de fragilização do princípio que marca a gestão; nesse caso, o princípio do regime de colaboração.

Assim, partimos do entendimento de que o regime de colaboração pressupõe "[....] compartilhar competências políticas, técnicas e financeiras para a execução de programas de manutenção e desenvolvimento da educação, de forma a convencionar a atuação dos entes federados sem ferir-thes a autonomia" (PARENTE apud CAMINI, 2010, p. 6). Essa compreensão de ações de compartilhamento comuns difere da delegação de responsabilidades, visto 226 que ressalta os princípios democráticos da

Na prática, tal efetivação do princípio colaborativo não ocorre de forma equânime, gerando uma sensação de fracasso no cumprimento do princípio constitucional. Abrúcio (2010), em estudo recente, constata tais dificuldades. Esse autor destaca que:

A sensação de fracasso do regime de colaboração incitou o governo federal a pensar em alternativas para o problema. Dois tipos de ação aconteceram. Um deles foi a criação de vários programas federais, desde o governo Itamar e intensificando-se nos mandatos dos dois últimos presidentes (FHC e Lula), com o propósito de criar parâmetros nacionais e combater desigualdades (ABRÚCIO, 2010, p. 62).

A relação estabelecida entre os entes federativos, desde a CF/1988, visando possibilitar maior integração regional e promover melhorias para a educação básica no país, toma rumos que fogem ao controle do ente central. Embora a legislação nacional defina as orientações das políticas educacionais, fundamentada em um regime de colaboração, sua praticidade se efetiva 
por meio de planos e programas focalizados, indo, nesse sentido, na contramão das proposições legais.

A legislação que delibera sobre maior efetivação do regime de colaboração ainda é frágil, no que diz respeito à forma de condução administrativa entre os entes federativos e das políticas que, efetivamente, promovam a responsabilização e o comprometimento conjunto e a melhoria da qualidade do ensino ofertado na educação básica.

Neste aspecto, concordamos com Fernandes (2013, p. 19) quando afirma que "[...] enquanto o regime de colaboração para a educação não for regulamentado por meio de Lei complementar, a colaboração entre União, Estados e Municípios terá dificuldades para ser efetivada".

Essas incertezas administrativas e a concentração de responsabilidades na promoção de programas sob a responsabilidade da União, descaracteriza o princípio basilar do regime de colaboração, inviabilizando ações educacionais concretas e eficazes, criando conflitos entre os demais entes federativos, dificultando a atuação desses entes no atendimento ao que foi proposto como sendo suas responsabilidades na melhoria da qualidade da educação básica no país.

Para Araúio (1998), devido a não efetivação concreta de um regime de colaboração que atenda à educação básica no país, os entes da federação atuam de acordo com seus interesses, e assim:

[...] as três instâncias da Federação podem operar (ou não) redes de ensino; podem financiar (ou não) a educação; e podem escolher onde desejam (ou não) atuar. Resultado: não existe uma instância do poder público que seja responsável (e responsabilizável) pela oferta (ou não) de ensino fundamental aos munícipes. Cada instância faz o que pode e o que quer, supostamente em regime de colaboração (ARAÚJO, 1998, p. 24).

A política social brasileira apresenta características e ideários que, no discurso, defendem a ação de colaboração entre os entes federativos, isto é, União, Estados, Municípios e o Distrito Federal devem propor e promover políticas públicas sociais que estabeleçam um regime de colaboração efetivo. Nesse aspecto, a legislação nacional é objetiva, pois orienta e reforça que os entes federativos devem estar integrados na efetivação do regime de colaboração no território nacional. 
O plano de ações articuladas e o regime de colaboração na gestão educacional em municípios paraenses

Cabe destacarmos, na legislação, os dispositivos que deliberam sobre a educação, que são de competência comum, conforme preceitua o artigo 23, inciso $V$, combinado com o caput do artigo 211 , os quais estabelecem que os membros da federação devem "proporcionar os meios de acesso à cultura, à educação e à ciência" e organizar os seus sistemas de ensino com vistas a um regime de colaboração (BRASIL, 1988).

No que tange às políticas educacionais e sua relação com o sistema político gerencial implantado no país, também a Constituição Federal (1988) propõe um sistema de colaboração entre os entes federados. Os artigos 208, 211 e 212 reforçam essa ideia quando mencionam que a União, Estados, Municípios e o Distrito Federal devem organizar seus sistemas de ensino em regime de colaboração. Esses artigos inclusive indicam uma previsão de investimentos, oriundos das transferências para a manutenção da educação básica.

A Emenda Constitucional 14/1996, ratifica e executa seus intentos na Lei n 9.424/1996 (que dispõe sobre o Fundef) e, posteriormente, a Ementa Constitucional 56/2006 (que cria o Fundeb e que será regulamentado pela Lei n 11 .494/2007 e pelo Decreto n 6.253/2007) define os procedimentos legais e sistemáticos de redistribuição do financiamento da educação, 228 especialmente da educação básica, determinando e (re) definindo a relação de responsabilidade dos entes federados com esse nível de ensino. Essas alterações no texto constitucional possibilitaram maior definição no papel dos entes federados que, na CF de 1988, não estava bem explícito.

A partir desse marco legal, a União passa a ter responsabilidade pelo sistema federal de ensino, assim como assume a assistência técnica e financeira aos entes federados, por meio dos programas elaborados pelo governo federal e repassados aos demais entes, para serem executados por esses. Dessa forma, a União exerce a função redistributiva e supletiva, conforme determina o parágrafo $1^{\circ}$ do artigo 211 da Constituição Federal de 1988, abaixo transcrito.

A união organizará o sistema federal de ensino e o dos territórios, financiará as instituições de ensino públicas federais e exercerá, em matéria educacional, função redistributiva e supletiva, de forma a garantir equalização de oportunidades educacionais e padrão mínimo de qualidade do ensino mediante assistência técnica financeira aos Estados, ao Distrito Federal e aos Municípios (BRASIL, 1988). 
A União se apresenta, no bojo da legislação, com o compromisso de exercer, sistematicamente, na relação entre os entes federados, sua função redistributiva dos recursos (aporte financeiro) e de apoio ou assistência técnica especializada aos Estados, ao Distrito Federal e aos Municípios, com vista a garantir educação básica de melhor qualidade. A Lei de Diretrizes e Bases da Educação Nacional (LDB/1996) ratifica essa obrigatoriedade quando no artigo $9^{\circ}$, inciso III delibera que a União deve, entre outras coisas, "[...] prestar assistência técnica e financeira aos Estados, ao Distrito Federal e aos Municípios para o desenvolvimento de seus sistemas de ensino e o atendimento prioritário à escolaridade obrigatória, exercendo sua função redistributiva e supletiva" (BRASIL, 1996).

pressuposto da função redistributiva da União para os demais entes federativos já havia sido estabelecido, na Constituição Federal de 1988, ratificando, assim, que a ela cabe o exercício dessa função em relação aos demais entes federativos quando exara no parágrafo $1^{\circ}$ do artigo 211 que a União "[...] exercerá, em matéria educacional, função redistributiva e supletiva [...] mediante assistência técnica e financeira aos Estados, ao Distrito Federal e aos Municípios" (BRASIL, 1988).

A LDB/ 1996 também destaca que a União deve exercer a função de coordenação das políticas educacionais e, ainda, atender aos demais entes regionais com ações formativas que articulem seu papel de promotora de fomento, visando primar pela qualidade da educação no território nacional. $\bigcirc$ parágrafo único do artigo $8^{\circ}$, da LDB exara, neste sentido, que "Caberá à União a coordenação da política nacional de educação, articulando os diferentes níveis e sistemas e exercendo função normativa, redistributiva e supletiva em relação às demais instâncias educacionais" (BRASIL, 1996).

Concomitante a isso, a LDB, em seu artigo 75, considerando a necessidade de corrigir as disparidades regionais e garantir um padrão mínimo de qualidade na educação nacional ratifica que "a ação supletiva e redistributiva da União e dos Estados será exercida de modo a corrigir, progressivamente, as disparidades de acesso e garantir o padrão mínimo de qualidade de ensino" (BRASIL, 1996).

Ao analisarmos o teor das discussões sobre o Plano de Desenvolvimento da Educação (PDE), que estão presentes no livro "Plano de Desenvolvimento da Educação: Razões, princípios e programas", podemos ter uma noção sobre os 
O plano de ações articuladas e o regime de colaboração na gestão educacional em municípios paraenses

interesses estatais com esse novo macro do programa, lançado com o discurso de que efetivaria a aceleração do crescimento nacional na área educacional. Tal afirmativa é confirmada na apresentação do livro quando, o Presidente da República à época, Luís Inácio Lula da Silva, afirma que "[...] a educação, é um caminho sólido para o Brasil crescer beneficiando todo o nosso povo. $\bigcirc$ PDE é um passo grandioso neste sentido" (SILVA, 2008, p. 3).

O discurso presente nos documentos é o de que o PDE é "mais do que a tradução instrumental do Plano Nacional de Educação" e, ainda, que o PDE é

O plano do executivo, como conjunto de programas que visa, dar consequência às metas quantitativas estabelecidas naquele diploma legal (PNE/200 1), mas os enlaces conceituais propostos tornam evidente que não se trata, quanto à qualidade, de uma execução marcada pela neutralidade (BRASIL, 2007, p. 7).

No que concerne aos princípios do regime de colaboração presentes no documento balizador desse programa, o texto do documento oficial salienta que:

O PDE busca, de uma perspectiva sistêmica, dar consequência, em regime de colaboração, ás normas gerais da educação na articulação com o desenvolvimento socioeconômico que se realiza no território, ordenado segundo a lógica do arranjo educativo local, regional ou nacional (BRASIL, 2007, p. 11 ).

No aspecto da efetivação de ações que permitam uma maior distribuição de recursos aos entes regionais, com vista à concretização plena do Regime de colaboração, o PDE reconhece as limitações financeiras desses entes e salienta, portanto, que é preciso promover ações de transferências de recursos e apoio técnicos àqueles sistemas educacionais sub-regionais de menor poder aquisitivo.

Destacamos que o texto organizador, que apresenta as metas do PDE, condiciona, no entanto, esses auxílios para os sistemas dos entes federativos à "capacidade de avançar com suas próprias forças" e à exigência no "cumprimento de um plano de trabalho". Em outras palavras, o suporte técnico e financeiro que pode ser oferecido aos entes regionais, segundo o que destaca o MEC, está condicionado ao cumprimento das exigências propostas pelo 
governo federal. Assim, o PDE estabelece o regime de colaboração no aspecto de auxilio técnico e financeiro quando enfatiza que:

regime de colaboração deve prever o aumento das transferências automáticas de recursos às escolas e às redes educacionais que demonstrem capacidade de avançar com suas próprias forças e o aumento das transferências de recursos condicionados à elaboração e ao cumprimento de um plano de trabalho para as escolas e as redes educacionais que necessitem de apoio técnico e financeiro (BRASIL, 2007, p. 40).

As prerrogativas condicionais obrigatórias para que os entes e seus sistemas de ensino mereçam os repasses auxiliares de fomento técnico e financeiro da União, conforme propõe o texto balizador do PDE, destoam do conceito singular que ele apresenta em seu escopo. Para o PDE, o regime de colaboração significa "[...] compartilhar competências políticas, técnicas e financeiras para a execução de programas de manutenção e desenvolvimento da educação, de forma a concertar a atuação dos entes federados sem ferirthes a autonomia" (BRASIL, 2007, p. 10).

A nosso ver, o próprio governo federal não assimilou ainda o que seja, de fato, o regime de colaboração, pois, ao mesmo tempo que defende a partilha de competências políticas, técnicas e financeiras entre os entes federativos e a garantia da autonomia destes, impõe condições que, em certo aspecto, considerando as fragilidades financeiras presentes nos entes regionais, são quase que inexequíveis.

Plano de Metas compromisso Todos pela Educação - PMCTE, objetiva promover "[...] programas e ações de assistência técnica e financeira, visando à mobilização social pela melhoria da educação básica" (BRASIL, 2007). Para o MEC, a importância desse plano para a política educacional se dá porque

[...] inaugura um novo regime de colaboração, que busca concertar a atuação dos entes federados sem thes ferir a autonomia, envolvendo primordialmente a decisão política, a ação técnica e atendimento da demanda educacional, visando à melhoria dos indicadores educacionais. Trata-se de um compromisso fundado em vinte e oito diretrizes e consubstanciado em um plano de metas concretas, efetivas, que compartilha competências políticas, técnicas 
O plano de ações articuladas e o regime de colaboração na gestão educacional em municípios paraenses

e financeiras para a execução de programas de manutenção e desenvolvimento da educação básica (BRASIL, 2010).

A proposta de efetivação do regime de colaboração nas ações relativas ao campo educacional é exarada logo na abertura do Decreto 6.094, de 24 de abril de 2007, quando reitera que este "[...] dispõe sobre a implantação do Plano de Metas Compromisso Todos pela Educação, pela União, em regime de colaboração [... $]^{\prime \prime}$ e será ratificada logo no artigo $1^{\circ}$, que salienta ser o PMCTE "[...] uma conjugação dos esforços da União [...], atuando em regime de colaboração [...], em proveito da melhoria da qualidade da educação básica" (BRASIL, 2007).

Vale destacarmos que, embora o planejamento do PMCTE proponha uma ação colaborativa via alcance de metas e objetivos firmados no documento balizador, as ações e subações de interesse de todos os entes federativos, em nome de uma gestão compartilhada, estão centralizadas no governo central, isto é, as prerrogativas decisórias, de colaboração ou não, são de competência da União, cabendo aos demais membros federativos a assunção de responsabilidades, conforme os termos e contratos propostos, 232 para serem credenciados pelo Ministério da Educação.

Esse pressuposto de colaboração entre os entes federados, cuja centralidade do poder está no governo federal, é destacado por Camini (2010). Essa autora, ao examinar como se efetiva nos programas propostos para atender, minimamente, ao princípio colaborativo, afirma que

[...] a adesão ao Plano de Metas Compromisso, [...] demonstra o poder da União na indução de políticas às instâncias subnacionais, orientando inclusive a inclusão e participação de outros setores na elaboração e implementação dos planos, assumindo forma de ação que se poderia caracterizar como democracia consentida (CAMINI, 2010, p. 15, grifo nosso).

A obrigatoriedade da elaboração de um Plano de Ações Articuladas, conforme estabelece o PMCTE, faz referência à necessidade de possibilitar um diagnóstico sistemático e mais próximo da realidade de cada ente que aderiu ao plano, objetivando, com isso, a prestação de assistência, conforme previsto nos termos de convênios e cooperação. Os direcionamentos previstos sobre o 
princípio de atuação colaborativa ente os entes estão mantidos e reforçados no PAR.

Essa orientação pode ser mais bem explicitada nas linhas da legislação (Decreto n ${ }^{\circ}$ 6.094), quando ratifica na seção II, artigo $9^{\circ}$, parágrafo $2^{\circ}$, os quais se referem ao PAR, que "[...] a partir do diagnóstico, o ente elaborará - PAR, com auxílio da equipe técnica, que identificará as medidas mais apropriadas para a gestão do sistema, com vistas à melhoria da qualidade da educação básica" (BRASIL, 2007).

\section{Regime de colaboração $x$ gestão educacional do PAR: compartilhamento de poder ou contrato de gestão?}

primeiro passo, na direção do esclarecimento das aparências presentes na forma governamental de se relacionar com os entes subnacionais e quais os contornos de como administra as políticas educacionais, é definirmos, de modo elementar, como se efetiva a gestão educacional e o que é, de fato, um contrato de gestão.

Cabe destacarmos que a administração, ou gestão educacional, não é estabelecida à parte das relações sociais existentes, ou seja, ocorre, em especial, em contextos determinados pelas forças e contradições existentes na própria sociedade. Desse modo, embora os termos gestão e administração possam ser entendidos como sinônimos, abarcam significados distintos a depender dos projetos defendidos pelos sujeitos governantes e suas ideologias político-partidárias, sua forma de compreensão dos sistemas de governo que, em tese, serão determinantes para gerir toda a estrutura estatal, inclusive espraiando-se pela política educacional.

Corroborando esse entendimento sobre o princípio conceitual de gestão /ou administração, Chaves, Gutierres, Mendes e Ribeiro (2014, p. 5) afirmam que "a administração/gestão educacional não se dá no vazio, mas em condições históricas determinadas, expressando as contradições sociais e a correlação de forças existentes na sociedade, podendo contribuir tanto para a conservação como para a transformação social".

Nesse aspecto, definimos a gestão educacional como processo horizontal, no qual a comunidade acadêmica e os profissionais da educação se envolvem desde os primeiros passos na elaboração das proposições 
O plano de ações articuladas e o regime de colaboração na gestão educacional em municípios paraenses

educacionais até a consecução dos objetivos pretendidos pela política ou programa educativo. Corroborando esse princípio conceitual do termo gestão educacional, Luck (2010) salienta que

entendimento do conceito de gestão, portanto, por assentar-se sobre a maximização dos processos sociais como força e ímpeto para a promoção de mudanças, já pressupõe, em si, a ideia de participação, isto é, do trabalho associado e cooperativo de pessoas na análise de situações, na tomada de decisões sobre seu encaminhamento e na sua ação sobre elas, em conjunto, a partir de objetivos organizacionais entendidos e abraçados por todos (LUCK, 2010, p. 21).

Considerando as prerrogativas da assertiva apresentada por Luck (2010), que sintetiza uma ideia defendida pela literatura sobre a temática, compreendemos que a gestão educacional é uma forma de gerir as políticas públicas educacionais, na qual não se pode prescindir do envolvimento dos mais interessados com a temática, que são os sujeitos que representam a sociedade.

Não basta, apenas, conceituarmos os termos para adequar aos discursos políticos, ou ainda, a imposição por meio de Decretos e Leis para sua efetivação. Há necessidade urgente da prática efetiva para que, não somente no âmbito das escolas e dos sistemas, a gestão, enquanto forma organizativa, seja estabelecida e fortalecida, mas, sobretudo, que esses vieses democráticos e participativos se espraiem para as relações entre as instituições que compõem a federação; nesse caso, União, Estados, Distrito Federal e Municípios.

Destarte, é salutar compreendermos, ainda, a lógica da gestão no âmbito da relação federativa enquanto forma de gerir as políticas públicas educacionais, sob a forma de pacotes educacionais proposto aos Estados, Distrito Federal e Municípios pela União. Ademais, julgamos importante ressaltar que esse modelo de gestão é permeado por relações entre os entes federados, baseadas nos auspícios de um contrato de gestão.

Em termos de definição do que seja o contrato de gestão na administração pública, Oliveira (1996) afirma que esse instrumento de gestão implica um compromisso assumido por um ente, empresa ou órgão da esfera pública, no qual se exige dos signatários o cumprimento de metas e objetivos, em um tempo determinado. Definidas as cláusulas essenciais do contrato, o ente 
promotor "[...] concede autonomia de gestão para que o dirigente disponha da flexibilidade administrativa e financeira indispensável para uma gerência eficiente e eficaz".

Uma definição mais clara sobre contrato de gestão é exposta por Oliveira a seguir:

Contrato de Gestão (contrato de plano, de programa e de serviços, conforme nomenclaturas adotadas na França) é um compromisso institucional firmado entre o Poder Executivo do Estado e cada entidade governamental a ele subordinada, incluindo-se como entidade desde empresas estatais até órgãos da Administração indireta, autárquica e fundacional inclusive os da Administração direta. Pretende estimular a Gestão por Objetivos no âmbito do setor público, para que se constitua como eixo central da Administração Pública, deslocando-a dos controles meramente normativos (jurídicos, fiscais, orçamentários e tarifários), para o controle de fins ou de objetivos a atingir (OLIVEIRA, 1996, p. 60).

De acordo com esse conceito de gestão, a subordinação e o prisma por resultado e eficiência são elementos constituintes das relações administrativas. $\bigcirc$ princípio da mediação entre os iguais, como assevera a CF/ 1988 lart. 18 e 34), está subjugado. Entretanto, considerando essa formula propositiva, em muitos aspectos, os programas e planos dos últimos anos, gerados no Ministério da Educação, estão assemelhados a esses princípios na gestão das políticas educacionais.

As prerrogativas dos critérios formulados para que Estados, Distrito Federal e Municípios possam ser atendidos, nos aspectos técnicos e financeiros pela União, no que se refere, por exemplo, ao que propõe o Plano de Desenvolvimento da Educação - PDE e suas 28 diretrizes, perpassa por esse viés da assunção da assinatura do contrato de gestão, no qual os entes sub-regionais (Estados, Distrito Federal e Municípios) aceitam as condições contratuais que, a nosso ver, contribuem para que lhes seja subtraída sua autonomia.

aspecto voluntário do convênio/contrato proposto é contraditório, pois as regras definidas não possibilitam ao ente concordante sugerir ou promover alterações e reformulações do termo, cabendo, unicamente, ao ente central essa atribuição. 
Nesse sentido, a obrigatoriedade (condição sine qua non), velada no Decreto, efetiva-se na execução do plano, já que, sem a devida assinatura do contrato/termo de adesão pelos gestores subnacionais, os subsídios técnicos e/ou financeiros previstos não poderão ser logrados. Isso implica prejuízos (sobretudo, financeiros) ou o alijamento daqueles que não se submeterem ao rito contratual, confirmando uma arbitrariedade e não uma colaboração.

Nessa direção, consideramos importante frisar que o processo de elaboração do PAR, nos municípios paraenses investigados², apresentou grandes dificuldades devido ao pouco tempo para execução do preenchimento do sistema.

Quando analisarmos a relação estabelecida entre os entes federados no processo de elaboração do PAR nesses municípios, ficou evidenciado, nas falas dos sujeitos, que todos tiveram dificuldades em preencher o formulário on-line, o qual foi realizado em média em dois dias, devido ao tempo curto e à falta de formação técnica específica para lidar com o preenchimento a plataforma.

É válido acrescentarmos que os entrevistados também mencionaram que o esforço em aderir ao PAR estava relacionado com o medo e/ou receio de perder os recursos; assim, se sentiam obrigados a aderir para manter os repasses como ficou evidenciado nas falas dos entrevistados de Belém e Castanhal:

O Par 2007-20 11 teve uma elaboração muito atropelada. Às vésperas do prazo encerrar nós recebemos a presença de um técnico que buscou o secretário de educação e explicou sobre o PAR, pois o município precisava fazer a adesão para não ter determinados recursos bloqueados pelo governo federal e que ele estava lá já para iniciar a elaboração conosco. Então o PAR 2007-201 1 foi elaborado em dois dias. Assim, o secretário de Educação convocou toda a sua assessoria e solicitou que todos ficassem na secretaria por dois dias e assim o técnico nos orientou para a elaboração do PAR (TÉCNICO 3, 2015).

$[\ldots]$

A grande dificuldade do não conhecimento do sistema, o ministério colocou um sistema que no início era complexo né, e ninguém tinha informações sobre isso, formação, saber como é que vai, como é que eu vou abrir o sistema, mexer, senha, acesso, janelas, abre aqui, abre ali, acompa... O PAR inicialmente era confuso e complicado pra gente entender essa, essa organização, esse sistema 
como é que o ministério pensou. Depois não, depois na medida em que a gente foi mexendo, foi aprendendo, foi executando ai foi melhorando, ai a coisa foi melhorando, a gente, as pessoas foram dominando como usar isso daí né, então eu acho que a maior dificuldade foi não saber mexer no sistema, não saber como fazer (TÉCNICO 1, 2015).

Evidenciamos, na fala dos sujeitos entrevistados, que o sistema informatizado se apresentou como elemento que dificultou o preenchimento do sistema em razão de sua complexidade, uma vez que não houve um treinamento específico para essa tarefa pelo MEC. Notamos, ainda, que a preocupação dos gestores municipais estava em não perder recursos, consequentemente, o preenchimento ocorreu de forma célere e sem um planejamento da própria equipe gestora do PAR.

Ao relacionarmos as características que a gestão educacional assume no Plano de Ações Articuladas, identificamos que, no PAR 2007/201 1, a gestão educacional estava subdividida em cinco grandes áreas. Os dados demonstram que a maioria das ações geradas estão na área da Gestão Democrática lque contempla indicadores relacionados ao funcionamento do Conselho Escolar, Conselho de Alimentação, Conselho Municipal de Educação, existência de projeto pedagógico e Plano Municipal de Educação, critérios para eleição de diretores, Plano de carreira do Magistério, plano de carreira para profissionais de apoio escolar e, estágio probatório).

No gráfico 1 a seguir, apresentamos as áreas que compõem a gestão educacional e a distribuição das ações geradas nos municípios paraenses

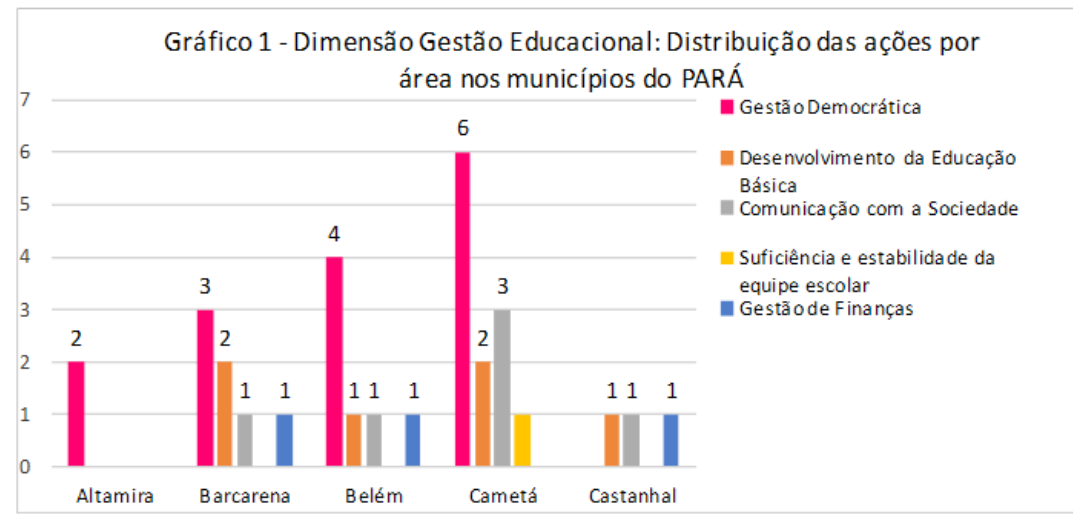

Fonte: Documentos do PAR dos municípios. 
O plano de ações articuladas e o regime de colaboração na gestão educacional em municípios paraenses

Destacam-se Cametá, Belém e Barcarena. Esses municípios apresentaram os maiores números de ações para essa área e Castanhal que foi o único município que não gerou ação.

Na tabela 1 abaixo, apresentamos uma síntese das áreas que compõem a Gestão Educacional, bem como o número de ações que foram geradas no PAR 2007/2011 e o nível de competência para execução dessas.

\section{Tabela 1}

Nível de competência para execução das ações por áreas da dimensão gestão educacional nos cinco municípios paraenses

\begin{tabular}{|c|c|c|}
\hline Área & $\begin{array}{c}\text { Competência Municipal } \\
\text { - Ações }\end{array}$ & Competência MEC - Ações \\
\hline $\begin{array}{c}\text { Gestão democrática: articu- } \\
\text { lação e desenvolvimento dos } \\
\text { sistemas de ensino }\end{array}$ & 20 & $\begin{array}{c}3 \\
\text { MEC/PDE } \\
\text { MEC/PNE/MEC }\end{array}$ \\
\hline $\begin{array}{c}\text { Desenvolvimento da educação } \\
\text { básica }\end{array}$ & 3 & $\begin{array}{c}2 \\
\text { MEC/MAIS } \\
\text { EDUCAÇÃO MEC/SEED }\end{array}$ \\
\hline Comunicação com a sociedade & 4 & $\begin{array}{c}1 \\
\text { MEC/ESCOLA ABERTA }\end{array}$ \\
\hline $\begin{array}{c}\text { Suficiência e estabilidade da } \\
\text { equipe escolar }\end{array}$ & 0 & 0 \\
\hline Gestão de finanças & 1 & 0 \\
\hline TOTAL & 28 & 6 \\
\hline
\end{tabular}

Fonte: Documento do PAR dos municípios.

Observamos que as ações e subações que constam no PAR dos cinco municípios paraenses analisados são, em sua maioria, de competência dos municípios. As ações de competência do MEC estão todas relacionadas à qualificação ou formação mediante programas federais já existentes, como Programa Mais Educação; o Programa Rádio Escola; Programa Escola Aberta, Programa Nacional de Fortalecimento dos Conselhos Escolares.

Aliado a isso, ao identificarmos as ações e subações geradas no que tange à área da gestão educacional, observamos que várias dessas ações foram exatamente idênticas para os cinco municípios aqui investigados. Vale frisar que as repetições das ações estão relacionadas às tarefas ligadas a 
programas nacionais já existentes, como, por exemplo: oferecimento de formação de gestores em cursos a distância; formação de conselheiros escolares; realização de reunião com a comunidade escolar para proposição e/ ou sensibilização acerca de algum elemento democrático, entre outros. Essa padronização das ações para contextos educacionais diversos demonstra indícios de instrumentalização do planejamento educacional.

Tal cenário nos leva a refletir sobre a autonomia dos municípios em propor ações que concretamente estejam articuladas às necessidades locais, pois se sabe que, apesar de estarem localizados no mesmo estado, os cinco entes, aqui investigados, possuem particularidades que devem ser consideradas no momento do planejamento e da gestão educacional.

A dinâmica existente na geração de ações de forma instrumental evidencia a limitada participação social haja vista que a elaboração do PAR se reduziu ao preenchimento e diagnóstico da realidade efetivado por técnico ou pequena equipe, influenciando diretamente no próprio conceito de regime de colaboração, discutido anteriormente, que se distancia da perspectiva de cooperação. Considerando que as ações são, em sua grande maioria, de competência municipal, há uma forte orientação da responsabilização de tarefas padronizadas para esses entes cumprirem eletronicamente.

resultado dessa prática instrumental de planejamento e de modelo gestão educacional, desarticulada da realidade concreta dos municípios paraenses, implica a materialização de formas gerenciais de gestão que não incluem as premissas da autonomia e a participação coletiva para a tomada de decisões, e consequentemente, interfere na adoção de elementos indispensáveis para a democratização da gestão.

Nessa direção, ao indagarmos os técnicos que participaram da equipe responsável pela elaboração e acompanhamento do PAR sobre as formações realizadas e oferecidas pelo MEC e a relação com o desenvolvimento das ações dos diferentes indicadores da dimensão da gestão educacional, o entrevistado de Altamira (2015), ao se referir sobre o acompanhamento dos conselhos escolares, destacou:

Nunca fui capacitada e nunca participei de nenhuma capacitação, assim do Governo Federal, nem do município, aprendi assim: aprendi aprendendo. Outra questão é a questão dos membros mais frequentes e atuantes, isso também é muito difícil, porque os pais 
O plano de ações articuladas e o regime de colaboração na gestão educacional em municípios paraenses

geralmente nunca compareciam nas reuniões, os representantes de pais. É, as pessoas parecem que não dão muita importância aos conselhos, a gente ver assim, pelo menos o de merenda a gente não via grande participação. Você tem que tá ligando, marca reunião e não dá quórum, desse jeito, a participação não é muito grande não (TÉCNICO 2, 2015).

Os demais entrevistados mencionaram em suas falas que ocorre acompanhamento e este é realizado por equipe técnica já vinculada às secretarias e auxiliam as escolas quanto ao funcionamento dos conselhos escolares, elaboração do projeto pedagógico e demais ações relacionadas aos indicadores que compõem a dimensão gestão educacional. Acrescentamos que a partir das falas dos entrevistados se evidenciou que não há uma comissão de acompanhamento das ações e, em alguns municípios paraenses, não há relatório de monitoramento.

Quando questionados sobre os recursos recebidos da União para execução dos programas educacionais que são desenvolvidos nas escolas, em todos os municípios investigados foi identificado que a secretaria de educação desenvolve alguns projetos, especialmente, relacionados a oferecer atividades 240 no contraturno (principalmente Belém e Altamira), mas essencialmente vindo de programas federais. Conforme o entrevistado de Belém:

Hoje são todos do Ministério da Educação, (...). Agora a escola tem muitos projetos, ela não tem só o Mais Educação; tem Esporte na escola; Atleta; tem PDE Educação Básica; tem o Acessibilidade; Proinfo; um conjunto de programas do Ministério de Educação que financiam as atividades da escola; e o dinheiro vai direto pra escola, por isso que tem que ter o Conselho Escolar. Os recursos são oriundos do Ministério da Educação (TÉCNICO 1, 2015).

Os dados coletados indicam que há uma relação de subordinação dos municípios ao governo federal, principalmente no aspecto financeiro, os quais dependem dos repasses federais a ponto de consensuarem e se submeterem a qualquer política determinada pela União. Tal relação se contrapõe, inclusive, a essência do regime de colaboração, e os princípios democráticos de autonomia e participação.

Consideramos importante enfatizar que, na dinâmica de ações geradas e na execução das subações estabelecidas, é perceptível o prevalecimento 
da delegação de tarefas, contrapondo a perspectiva de descentralização do poder e mesmo o discurso de colaboração. Coube aos municípios paraenses não a autonomia para decidir coletivamente sobre as ações mais adequadas para cada realidade local, mas, efetivamente, a responsabilização na execução dessas.

\section{Conclusão}

Os dados expostos mostraram que prevalece uma relação centralizada do poder central na sua relação com Estados, Distrito Federal e Municípios que, por sua vez, se colocam numa posição de obediência às determinações emanadas pela União por meio de planos e programas. Tal relação de subordinação pode ser explicada pela necessidade de ajuda financeira dos municípios em face das suas dificuldades orçamentárias e desigualdade na capacidade econômica desses entes, salvo as poucas exceções e foi uma motivação para aderir ao PAR.

Nesse aspecto, os fundamentos do regime de colaboração são depreendidos de um autêntico princípio federativo, em que, embora as legislações atinentes à política educacional (desde a CF/1988, passando pela LDB, pelo PDE, pelo PMCTE e pelo PAR) apresentem dispositivos na direção da efetivação do referido regime, este não acontece na prática.

Cabe destacarmos que um legítimo regime de colaboração se efetiva com a descentralização de poder, com a autonomia nas decisões, com a observância da paridade hierárquica e com o fortalecimento das relações do pacto federativo. É importante ressaltarmos que num Estado de Direito Democrático, que defende a colaboração e o compartilhamento das decisões, a participação social é indispensável.

Nesse sentido, o estudo indicou que o PAR se distancia da participação, não permitindo a construção coletiva, que, no caso dos municípios paraenses, desde a elaboração do PAR ocorreu de forma autocrática, e as ações estabelecidas ocorreram de forma verticalizada e padronizada, fundamentada na delegação das tarefas e também limitando a autonomia dos entes federados na proposição de ações ligadas às necessidades específicas de cada contexto. 
Foi detectado um distanciamento dos princípios elementares do regime colaborativo nos municípios paraenses, com ênfase em políticas educacionais que primam por uma dependência aos programas nacionais já existentes. Essa dependência, por sua vez, implica a instrumentalização da autonomia federativa e, consequentemente, a subordinação dos entes federativos à União que se reforça e se fortalece, enquanto governo central, promovendo uma relação centralizada, concentrada e regulada.

estudo evidenciou que predomina uma concepção de gestão centralizada e verticalizada das políticas educacionais que não se coaduna como uma efetiva ação pública que promova, conforme prevê a constituição, um verdadeiro regime de colaboração. Trata-se, na realidade, de políticas contratuais, gestadas pelo órgão central da federação, se aproximando do modelo gerencial de gestão, fragilizando a relação do pacto federativo, sem a eficácia da propalada relação colaborativa, em nome da manutenção do poder no centro.

Na dinâmica de adesão e na implementação das ações constituídas por meio do PAR, a tendência à responsabilização por parte dos entes municipais, que configura mais num contrato de gestão do que o fomento e

242 efetivação de um princípio constitucional inspirado no ideário democrático. Em uma nação que instituiu a gestão democrática enquanto princípio constitutivo e um regime de responsabilidades para o compartilhamento das competências, há, no caso paraense, um distanciamento entre o ideal e o concreto.

\section{Nota}

1 Os cinco municípios selecionados para a realização da pesquisa tendo como critério os índices obtidos no ldeb (maior e menor valor), são: Altamira, Barcarena, Belém, Cametá e Castanhal.

2 Pesquisa financiada pelo OBSERVATÓRIO DA EDUCAÇÃO da Capes.

$3 \bigcirc$ regime de colaboração entre a União federal com Municípios, Distrito Federal e Estados, visando à mobilização social pela melhoria da qualidade da educação básica foi estabelecido no Plano de Metas Todos pela Educação criado por meio do Decreto n 6094/2007, de 24 de abril de 2007. 


\section{Referências}

ABRÚClO, Fernando Luiz. A Dinâmica Federativa da Educação Brasileira: Diagnóstico e propostas de Aperfeiçoamento. In: OLIVEIRA, Romualdo Portela de; SANTANA, Wagner (Org.). Educação e federalismo no Brasil: combater as desigualdades, garantir a diversidade. Brasília: UNESCO, 2010.

ARAÚJO João Batista Oliveira e. Avanços e Impasses na educação: à guisa de balanço. Revista do Legislativo, Belo Horizonte, n. 21 , p. 16-27, jan./mar. 1998.

BRASIL. Lei $\mathbf{n}^{\circ}$ 9.424, de 24 de dezembro 1996. Dispõe sobre o Fundo de Manutenção e Desenvolvimento do Ensino Fundamental e de Valorização do Magistério, na forma prevista no art. 60, $\S 7^{\circ}$, do Ato das Disposições Constitucionais Transitórias, e dá outras providências. Disponível em: http://www.planalto.gov.br/ccivil_03/leis/L9424.htm. Acesso em: 30 out 2017 .

Ementa Constitucional 53, de 19 de dezembro de 2006. Dá nova redação aos arts. $7^{\circ}, 23,30,206,208,211$ e 212 da Constituição Federal e ao art. 60 do Ato das Disposições Constitucionais Transitórias. Disponível em: http://www.planalto.gov.br/ ccivil_03/constituicao/emendas/emc/emc53.htm. Acesso em: 30 out 2017.

Constituição da República Federativa do Brasil. Promulgada em 5 de outubro de

1988. Brasilia: Senador Federal, 2008.

. Decreto $n^{\circ}$. 6.094, de 24 de abril de 2007. Dispõe sobre a implementação do Plano de Metas Compromisso Todos pela Educação, pela União, em regime de colaboração com Municípios, Distrito Federal e Estados. Diário Oficial [da] República Federativa do Brasil, Poder Executivo, Brasília, DF, 24 abr. 2007.

Lei n $^{\circ}$ 11.494, de 20 junho de 2007. Regulamenta o Fundo de Manutenção

e Desenvolvimento da Educação Básica e de Valorização dos Profissionais da Educação - FUNDEB, de que trata o art. 60 do Ato das Disposições Constitucionais Transitórias. Disponível em: http://www.planalto.gov.br/ccivil_03/_ato2007-2010/2007/lei/ 11 1494.htm. Acesso em: 30 out 2017.

Decreto ${ }^{\circ}$ 6.253, de 13 de novembro de 2007. Dispõe sobre o Fundo de Manutenção e Desenvolvimento da Educação Básica e de Valorização dos Profissionais da Educação FUNDEB, regulamenta a Lei no 11 .494, de 20 de junho de 2007, e dá outras providências. Disponível em: http://www.planalto.gov.br/ccivil_03/_ato2007/2010/2007/decreto/ d6253.htm. Acesso em: 30 out 2017. 
O plano de ações articuladas e o regime de colaboração na gestão educacional em municípios paraenses

Plano de Ações Articuladas. Guia prático de ações para municípios. Brasília: Ministério da Educação, 2011.

Ministério da Educação. Compromisso Todos pela Educação: passo a passo, 2007. Brasília: Secretaria de Educação Básica - SEB/MEC, 2008.

Ministério da Educação. Plano de Desenvolvimento da Educação (PDE). 2007. Disponível em: http//www.mec.gov.br. Acesso: em: 10 jan. 2008.

Lei n 9.394, de 20 de dezembro de 1996. Estabelece as Diretrizes e Bases da Educação Nacional. Diário Oficial [da] República Federativa do Brasil, Poder Executivo, Brasilia, DF, 23 dez. 1996. Disponível em: http://www.planalto.gov.br/ccivil_03/LEIS/ 19394.htm. Acesso em: 2 jun. 2013.

CAMINI, Lucia. Gestão educacional e a relação entre entes federados na política educacional do PDE/Plano de Metas Compromisso Todos pela Educação. 2009. 294f. Tese (Doutorado em Educação) - Programa de Pós-Graduação em Educação, Universidade Federal do Rio Grande do Sul, Porto Alegre, 2009.

A relação do MEC com os entes federados na implantação do PDE/Plano de Metas Compromisso Todos pela Educação: Tensões e Tendências. Jornal de Políticas 244 Educacionais, Curitiba, n. 8, p. 3-13, jul./dez. 2010.

CASSINI, Simone Alves. Federação e educação no Brasil: a atuação do poder legislativo nacional para regulamentação do regime de colaboração. $2011.143 f$. Dissertação (Mestrado em Educação) - Programa de Pós-Graduação em Educação da UFES. Vitória, 2011.

CHAVES, Vera Lucia Jacob; GUTIERRES, Dalva Valente Guimarães; MENDES, Odete da Cruz; RIBEIRO, Maria Edilene da Silva. Gestão da Educação: Uma revisão conceitual na perspectiva de análise do Plano de Ações Articuladas - PAR. In: CONGRESSO IBERO-AMERICANO DE POLITICA E ADMINISTRAÇÃO DA EDUCAÇÃO, 4; 2014 , Porto. Anais... Disponível em: hitp://www.anpae.org.br/IBERO_AMERICANO_IV/GT1/GT1_Comunicacao/ VeraLuciajacobChaves_GT1_integral.pdf. Acesso em: 30 out 2017.

FERNANDES, Thamyres Wan de Pol. Regime de Colaboração: o contexto histórico das ações e das práticas em Educação. Educação em Foco, Juiz de Fora, v 1, n. 3, p. 153-176, nov. $2012 /$ fev. 2013.

HAGUETE, André. Da municipalização à ação federativa coordenada. Em Aberto, Brasília, v. 8, n. 44, p. 23-30, Disponível em: http://www.rbep.inep.gov.br/index.php/emaberto/ article/. Acesso em: 20 out. 2014. 
LUCK, Heloísa. A gestão participativa na escola. 8 ed. Petrópolis: Vozes, 2010.

OLIVEIRA, Jose Almi. Contrato de gestão considerações sobre a sua viabilidade na administração educacional. 1996. Dissertação (Mestrado em Administração) - Fundação Getúlio Vargas. Disponivel em: http://bibliotecadigital.fgr.br/dspace/handle/10438/8462. Acesso em: 31 maio 2016.

SILVA, Luís Inácio Lula da. Apresentação. In: O Plano de Desenvolvimento da Educação: razões, princípios e programas. Ministério da Educação. Brasil, 2008, p. 3. Disponível em http://portal.mec.gov.br/arquivos/livro/livro.pdf. Acesso em: 31 maio 2016.

TÉCNICO 1. Entrevista. Belém (Pará), 22 jun. 2015.

TÉCNICO 2. Entrevista. Altamira (Pará), 14 set. 2015.

TÉCNICO 3. Entrevista. Castanhal (Pará), 10 set. 2015.

WERLE, Flávia Obino Correa. Sistema municipal de ensino e regime de colaboração. liuí: Editora Unijuí, 2006.

Prof. Dr. Laurimar de Matos Farias Secretaria do Estado de Educação do Pará Grupo de Estudo e Pesquisa sobre Educação Superior - GEPES/UFPA E-maill laurimatos72@yahoo.com.br

Profa. Dr ${ }^{a}$. Vera Lúcia Jacob Chaves Universidade Federal do Pará Instituto de Ciências da Educação

Programa de Pós-Graduação em Educação Coordenadora do Grupo de Estudo e Pesquisa sobre Educação Superior - GEPES/ UFPA Bolsista Produtividade do CNPq E-mail | veraluciajacob@gmail.com

Profa. Ms. Valéria Silva de Moraes Novais Universidade do Estado do Amapá 
Artigo

O plano de ações articuladas e o regime de colaboração na gestão educacional em municípios paraenses

Doutoranda em Educação da Universidade Federal do Pará Grupo de Estudo e Pesquisa sobre Educação Superior - GEPES/UFPA

E-mail | valeria.veap@yahoo.com.br

Recebido 27 set. 2017

Aceito 30 out. 2017 